\title{
Duplication of Plasmid-Borne Nitrite Reductase Gene nirK in the Wheat-Associated Plant Growth-Promoting Rhizobacterium Azospirillum brasilense Sp245
}

\author{
Joël F. Pothier, Claire Prigent-Combaret, Jacqueline Haurat, Yvan Moënne-Loccoz, and \\ Florence Wisniewski-Dyé \\ Université de Lyon, Lyon, F-69003, France; Université Lyon 1, Lyon, F-69003, France; CNRS, UMR 5557, \\ Ecologie Microbienne, Villeurbanne, F-69622, France; IFR 41, Villeurbanne, F-69622, France \\ Submitted 20 November 2007. Accepted 12 February 2008.
}

In the plant growth-promoting rhizobacterium Azospirillum brasilense Sp245, nitric oxide produced by denitrification could be a signal involved in stimulation of root branching, and the dissimilatory nitrite reductase gene nirK is upregulated on wheat roots. Here, it was found that Sp245 did not contain one copy of nirK but two (named nirK1 and nirK2), localized on two different plasmids, including one plasmid prone to rearrangements. Their deduced protein sequences displayed $99.2 \%$ identity but their promoter regions and upstream genetic environment differed. Phylogenetic studies revealed that nirK1 and nirK2 clustered next to most $\beta$-proteobacterial sequences rather than in the vicinity of other Azospirillum spp. and most $\alpha$-proteobacterial sequences, regardless of whether DNA or deduced protein sequences were used. This points to past horizontal gene transfers. Analysis of the number of nonsynonymous and synonymous substitutions per site indicated that nirK has been subjected to neutral selection in bacteria. The use of transcriptional fusions with $e g f p$, encoding an enhanced green fluorescent protein variant, revealed that both nirK1 and nirK2 promoter regions were upregulated in vitro under microaerobiosis or the presence of nitrite as well as on wheat roots. The analysis of nirK1 and nirK2 mutants revealed that the two genes were functional. Overall, results suggest that nirK has been acquired horizontally by $A$. brasilense $\mathrm{Sp} 245$ from a distant relative and underwent subsequent duplication; however, both paralogs remained functional and retained their upregulation by the plant partner.

Additional keywords: genome plasticity, nitrite reduction, PGPR.

Many plant-associated bacteria can perform denitrification, during which there is conversion of nitrate or nitrite to gaseous nitrogen oxides and finally to dinitrogen as the end product (Zumft 1997). This pathway is utilized as an alternative form of respiration under oxygen-limited conditions and is relevant for plant root colonization (Ghiglione et al. 2000), because such conditions occur readily in the rhizosphere (Højberg et al.

Corresponding author: F. Wisniewski-Dyé; Telephone: +33 4724458 89; Fax: +33 4724312 23; E-mail: wisniews@ biomserv.univ-lyon1.fr

This article is in the public domain and not copyrightable. It may be freely reprinted with customary crediting of the source. The American Phytopathological Society, 2008.
1999). A key step in this pathway is the formation of nitric oxide (NO) mediated by nitrite reductase. Two main classes of dissimilatory nitrite reductase (Nir) exist among denitrifying bacteria: the haem-cytochrome $c d_{1}$ type encoded by nirS genes and the copper-containing type encoded by nirK genes (Zumft 1997).

Dissimilatory nitrate reduction diminishes the amount of nitrate available for plant nutrition. In addition to its significance for nitrogen acquisition by the plant, denitrification by plant-associated bacteria also may have implications for plant development (Lamattina et al. 2003). Indeed, NO produced directly or indirectly by the $\alpha$-proteobacterial plant growthpromoting rhizobacterium (PGPR) Azospirillum brasilense Sp245 when colonizing tomato roots is involved in the stimulation of lateral root formation (Creus et al. 2005). Therefore, NO production might be another plant-beneficial trait displayed by Azospirillum PGPR in addition to associative nitrogen fixation (Bally and Elmerich 2006), phytohormone production (Costacurta and Vanderleyden 1995; Dobbelaere et al. 2001), deamination of the ethylene precursor 1-aminocyclopropane1-carboxylate (Blaha et al. 2006), and the biological control of phytoparasitic plants (Miché et al. 2000) or bacteria (Bashan and de-Bashan 2002). In model greenhouse experiments, wheat-Azospirillum spp. associations were shown to perform either denitrification or $\mathrm{N}_{2}$ fixation, depending on the availability of $\mathrm{NO}_{3}{ }^{-}$and $\mathrm{O}_{2}$ (Neuer et al. 1985).

A better understanding of plant-beneficial traits is important because Azospirillum spp. can increase growth and yield of different plant species and are used as inoculants in cereal production (Costacurta and Vanderleyden 1995; Dobbelaere et al. 2001). In the case of NO synthesis, little is known of the genetic determinants involved. Recently, the implementation of a global promoter-trapping approach based on differential fluorescence induction (DFI) in the presence of wheat seed extracts revealed a dissimilatory nitrite reductase gene, nirK, in the wheat isolate A. brasilense Sp245 (Pothier et al. 2007). This gene also was upregulated when the PGPR colonized wheat roots. NO is important for plant growth promotion and this was the first identification of nirK in A. brasilense; therefore, further work was carried out to characterize this gene.

In the course of this work, it was found that A. brasilense Sp245 possesses a second nirK-like gene, raising the question of its phylogenetic origin and whether these two genes are functional or not. Therefore, the objective of this study was to characterize the two nirK-like genes in A. brasilense Sp245. First, the two genes were mapped on the genome and their sequences analyzed. Second, their expression was monitored on 
plant roots using transcriptional fusions of their promoter region with egfp, encoding an enhanced green fluorescent protein variant. Third, inactivation mutants were constructed and compared based on $\mathrm{NO}_{2}^{-}$consumption and $\mathrm{N}_{2} \mathrm{O}$ production.

\section{RESULTS}

Evidence for two nirK genes in A. brasilense $\mathrm{Sp} 245$.

A nirK polymerase chain reaction (PCR) product first was obtained with primers F3905/F3906 (Table 1) designed from the partial nirK sequence already available (Pothier et al. 2007). Using this nirK PCR product as a probe on digested genomic DNA of A. brasilense Sp245, two Southern hybridization signals were obtained (Fig. 1), implying that the nirK gene was present in two copies. Because genes encoding denitrification enzymes may be located on plasmids (Zumft 1997), plasmids of $A$. brasilense Sp245 were separated using a modified Eckhardt gel technique (Fig. 2A) and hybridized with the nirK probe (Fig. 2B). Six replicons were found (Fig. 2A, lane 2), with sizes estimated at 150, 250,750, 800, and >1,000 kb (for two replicons, the largest not always visible on Eckhardt gels is likely to be the chromosome). Two hybridization signals were observed, corresponding to the $250-\mathrm{kb}$ plasmid and either the 750 - or $800-\mathrm{kb}$ plasmid (Fig. 2B, lane 2). Therefore, A. brasilense Sp245 contains two nirK genes localized on two different plasmids.

\section{Determination of entire nirK sequences of $A$. brasilense Sp245.}

To obtain the entire sequence and flanking regions of the nirK gene (termed nirKl) induced by wheat seed extracts (Pothier et al. 2007), first a genomic library of strain A. brasilense Sp245 was constructed and screened by PCR using primers F3787 and F3789 targeting nirK1 and its promoter, respectively (Table 1). Amplification products of the expected size were obtained with 5 of 650 library clones. From these clones, named pR2.62, pR2.63, pR2.64, pR2.65, and pR2.66, four different restriction patterns were retrieved; however, they all shared restriction fragments of similar sizes (data not shown). Second, the entire sequence of nirK1 of A. brasilense Sp245 and its surrounding environment (i.e., a region spanning over $2.4 \mathrm{~kb}$ ) were determined by genome walking using DNA from pR2.62 (Fig. 3A).

Because only one nirK genomic region was obtained, the Sp245 library was screened again, using primers (F3905/ F3906) amplifying an internal fragment of nirK. This led to the identification of another clone called pR2.67, in which the presence of nirK was confirmed by Southern experiments using the nirK internal probe (obtained with primers F3905 and F3906) and by sequencing. However, when PCR reactions were performed on pR2.67 with primers (i.e., F3787/F3789) targeting the previously characterized promoter of nirK1, no amplification product was obtained, suggesting that the two nirK genes did not share the same promoter region. The entire sequence of this second copy of nirK (termed nirK2) and its flanking regions (a region spanning over $3.6 \mathrm{~kb}$ ) was determined by genome walking using pR2.67 as a template (Fig. 3B).

\section{Genomic rearrangements affecting the replicon bearing nirK2.}

Previous work based on plasmid profiling also had revealed six plasmids in $A$. brasilense Sp245, but with a large discrepancy in size for certain plasmids (Kamneva et al. 2001; Katzy et al. 1998). Therefore, the plasmid content of the strain was compared (Fig. 2A) after having collected Sp245 from four other laboratories studying Azospirillum spp. (i.e. Knoxville [G. Alexandre, University of Tennessee], Paris [C. Elmerich, Institut Pasteur], Rehovot [Y. Okon, The Hebrew University], and Leuven [J. Vanderleyden, Catholic University]). Whereas all five

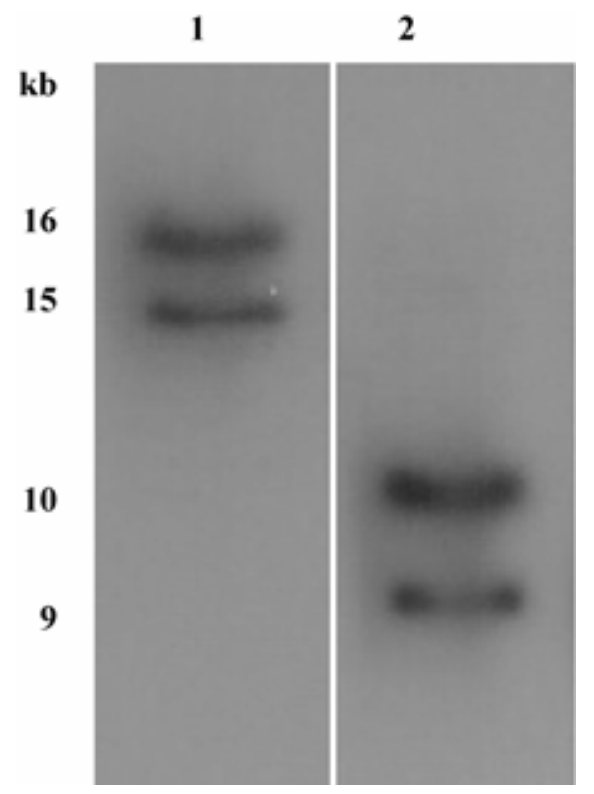

Fig. 1. Evidence for two nirK genes in Azospirillum brasilense Sp245. Southern hybridization of genomic DNA of A. brasilense Sp245. A 240-bp internal fragment of nirK was used as a probe. Lanes 1 and 2, DNA from Sp245 digested with BamHI and EcoRI, respectively.

Table 1. Primers and polymerase chain reaction conditions

\begin{tabular}{|c|c|c|c|}
\hline Primer name & Primer sequence & Nucleotide target $^{\mathrm{a}}$ & Reference \\
\hline F2603 (forward) & 5' CGGTTTACAAGCATAAAGC 3' & Multiple cloning site of pOT1e & Pothier et al. 2007 \\
\hline F2604 (reverse) & 5' CATTTTTTCTTCСТCСACTAG 3' & Multiple cloning site of pOT1e & Pothier et al. 2007 \\
\hline F3787 (reverse) & 5' GATCCGGGCGCGTTCGTCATGG 3' & coding region of $n i r K$ & This work \\
\hline F3789 (forward) & 5' TCTCGCGCTGGATGTCGCCAG 3' & Promoter region of nirKl & This work \\
\hline F3905 (forward) & $5^{\prime}$ TGTACGCCGAACCGAAGGTC $3^{\prime}$ & Coding region of nirK & This work \\
\hline F3906 (reverse) & 5' TCATGGACACGTTCACCGTG 3' & Coding region of nirK & This work \\
\hline F4437 (forward) & 5' GTGTCCTCAACATCCTGTCG 3' & Coding region of $\operatorname{car} R$ & This work \\
\hline F4438 (reverse) & 5' CCTTGCCGTGTGAAGCGCAT 3' & Coding region of $c a r R$ & This work \\
\hline F5302 (forward) & $5^{\prime}$ TGGGCAACATCGATTACGAG 3' & Promoter region of nirKl & This work \\
\hline F5303 (forward) & 5'CTGCGACTGCATCGATGCGA 3' & Promoter region of nirK2 & This work \\
\hline F5595 (reverse) & 5' TGTCCAGATAGCCCAGTAGC 3' & $\mathrm{Km}^{\mathrm{r}}$ cassette of $\mathrm{pKNOCK}-\mathrm{Km}$ & This work \\
\hline F5597 (forward) & 5' АСТТССТСАСТСТСАCAGGCA 3' & Promoter region of nirK1 & This work \\
\hline F5598 (forward) & 5' AACGGAAGTGATCGGAGCGT 3' & Promoter region of nirK2 & This work \\
\hline F5635 (forward) & 5' GCCCCCAAGACCCACAACGT 3' & Coding region of nirK & This work \\
\hline F5636 (forward) & $5^{\prime}$ TGAACGAGAATTCCTTGGTCTG 3' & Coding region of $n i r K$ & This work \\
\hline
\end{tabular}

${ }^{\mathrm{a}} \mathrm{Km}^{\mathrm{r}}=$ resistant to kanamycin. 
strains of Sp245 host three plasmids of 150, 750, and $800 \mathrm{~kb}$ and two replicons $>1,000 \mathrm{~kb}$ (Fig. $2 \mathrm{~A}, \mathrm{c}, \mathrm{f}, \mathrm{g}$, h, and o, respectively), several discrepancies were observed for the other plasmids, as follows. First, all strains of Sp245 except ours contain a 160-kb plasmid (i.e., Fig. 2A, d); second, a smaller plasmid of variable size could be observed in three Sp245 strains (i.e., Fig. $2 \mathrm{~A}$, a or b); third, only our strain carries a 250-kb plasmid (i.e., Fig. 2A, e).

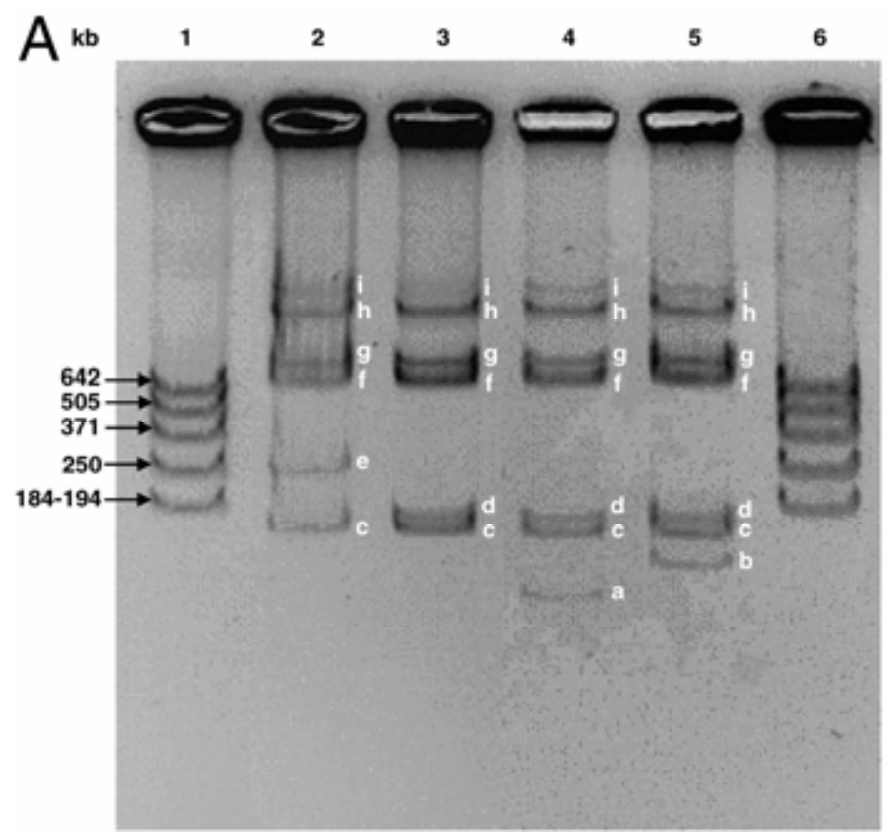

B

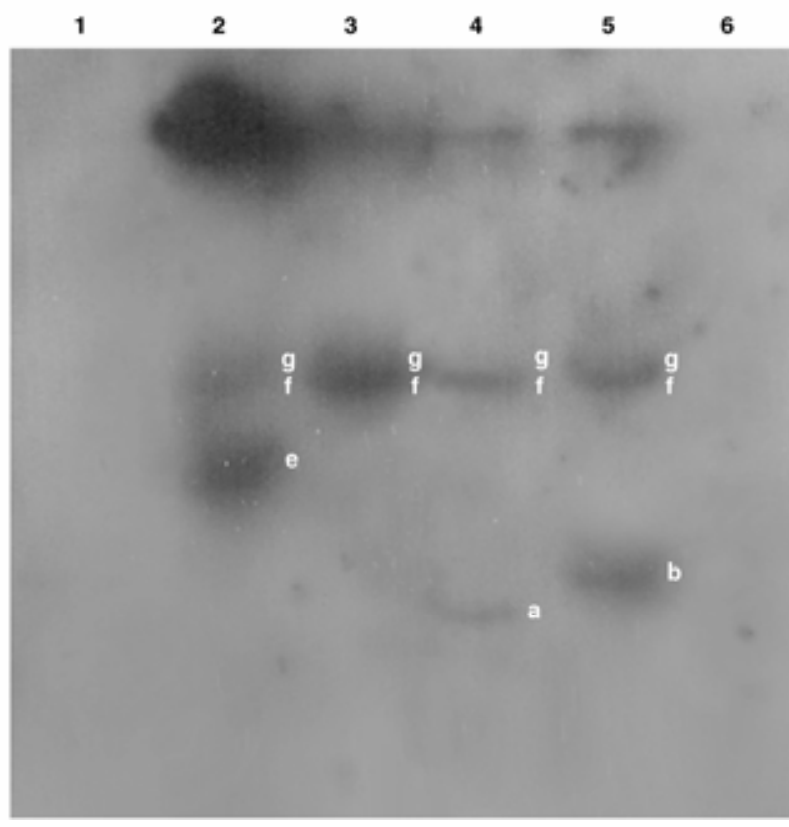

Fig. 2. Analysis of genomic rearrangements affecting the replicon bearing nirK2. A, Electrophoretic plasmid profiles of Azospirillum brasilense Sp245 strains kept in different laboratories; for example, in Lyon (lane 2), Knoxville (lane 3), Paris (lane 4), and Rehovot (lane 5). The marker strain Rhizobium etli CFN42 also is displayed (lanes 1 and 6). The plasmid profile of the Sp245 strain from Leuven (not shown) is identical to that of the Rehovot strain (lane 5). B, Southern hybridization of the plasmid profiles shown in panel A, using a 240-bp internal fragment of nirK as a probe.

A

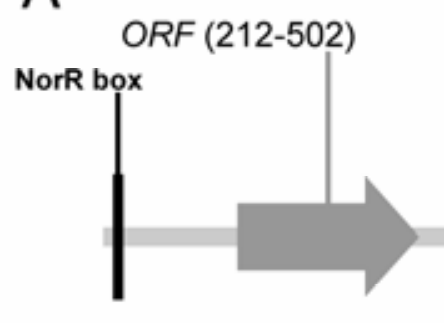

(212-502)

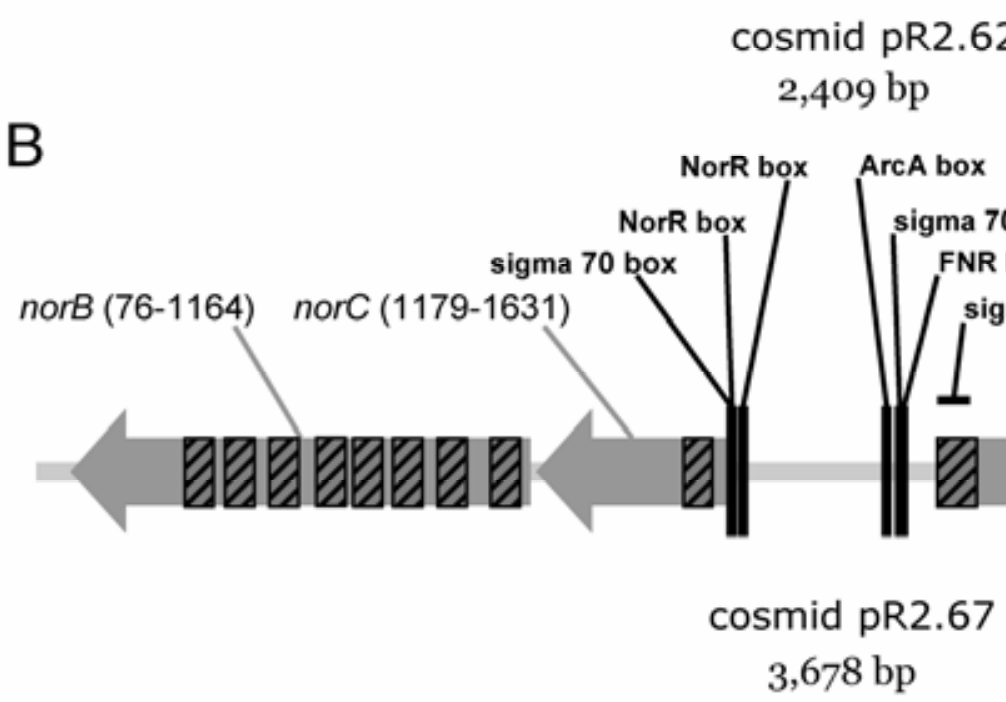

Fig. 3. Physical maps of the two nirK genes from Azospirillum brasilense Sp 245 and their respective environment. A, Physical map of a 2.4-kb region containing nirK1 that was obtained by genome walking using DNA from pR2.62. ORF = open reading frame and FNR $=$ fumarate-nitrate reduction. $\mathbf{B}$, Physical map of a 3.6-kb region containing nirK2 that was obtained by genome walking using DNA from pR2.67. Stripped boxes correspond to putative transmembrane helixes. 
A.brasil1

A.brasi12

Hi. denitr:

N.multifo

N. gonorrh

A. faecal1

R.sullae

A. cyclocl

A.xylosox

P.chloror

R.sphaero
A.brasil1

A.brasil2

H.denitri

N.multifo

N. gonorrh

A. faecall

R.sullae

A. cyclocl

A.xylosox

P.chloror

R.sphaero

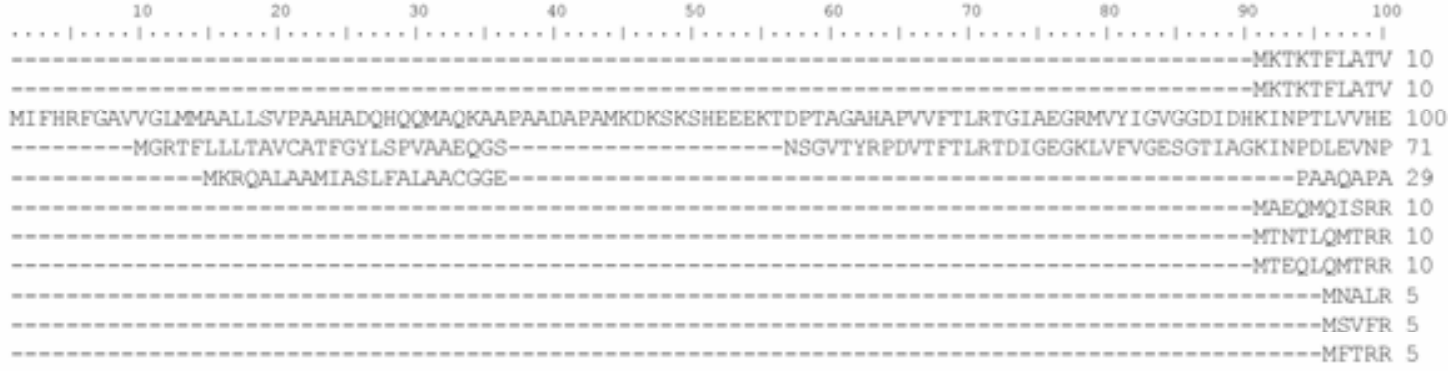

A.brasil1

A.brasil2

H. denitri

N.multifo

N.gonorrh

A. faecali

R.sullae

A. cycloci

A. xylosox

P.chloror

R.sphaero

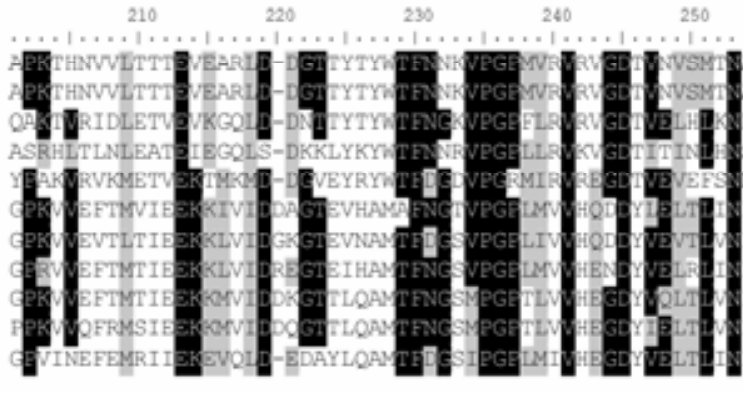

$270 \quad 260$

300

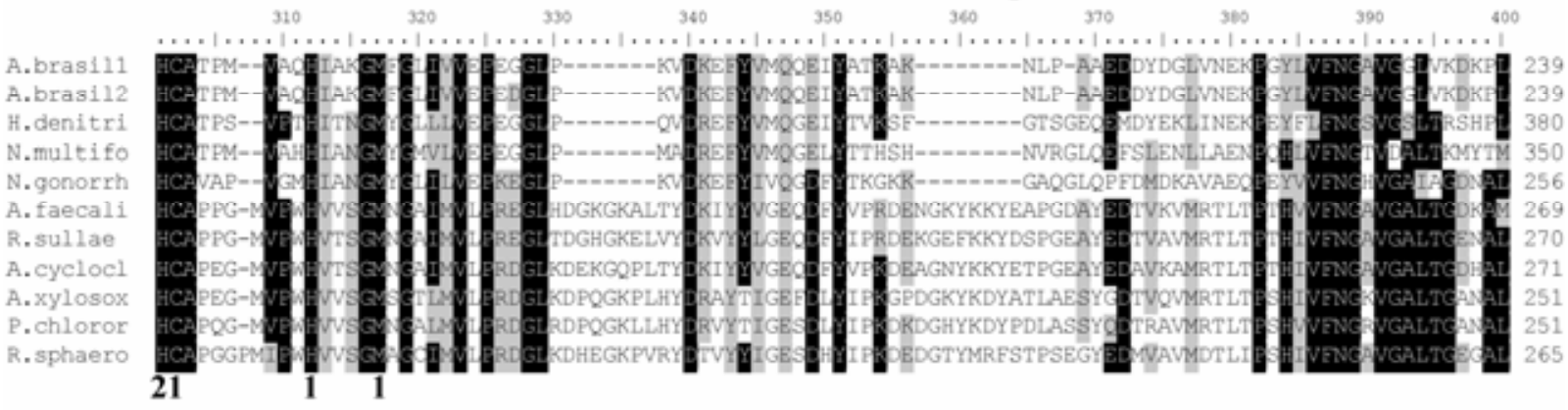

A.brasill

A.brasi12

H.denitri

N.multifo

N. gonorrh

A. faecal1

R.sullae

A. cyclocl

A.xylosox

P.chloror

R.sphaero

A.brasil1
A.brasil12
H.denitri
N.multifo
N.gonorrh
A.faecali
R.sullae
A.cyclocl
A.xylosox
P.chloror
R.sphaero
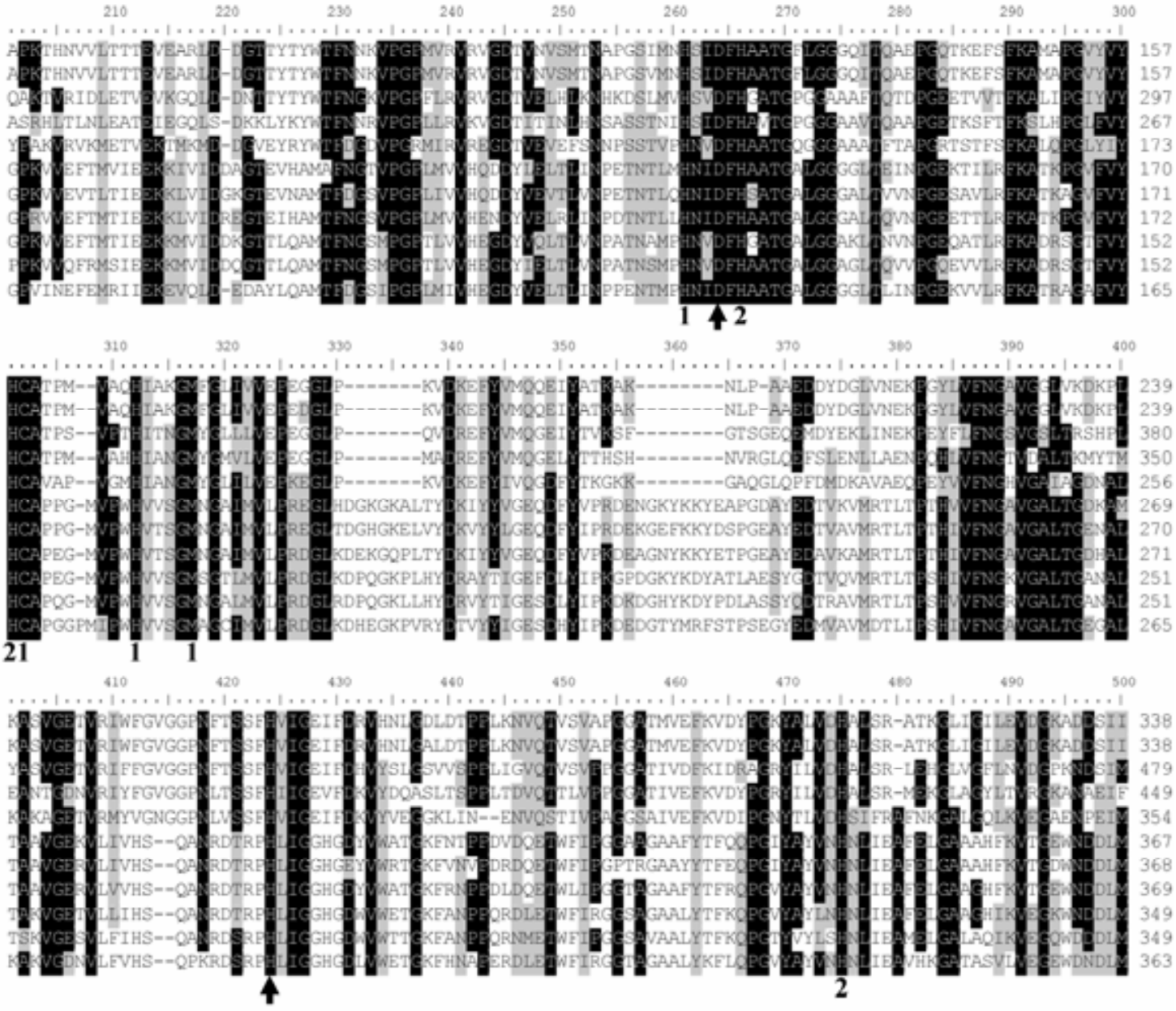

142

LDKSGDSRKQLGEMKH

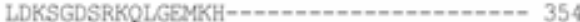

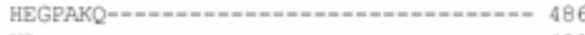

DTAYAGSGAASAPAASAPAASAPAASASEKSTY 392

TQKLSDTAYAGSGAASAPAASAPAASAPAASASEKSVY 392

TSVLAPSGT--_-_-_-_- 376

TTVRSPSGS-1-0-10-10- 376

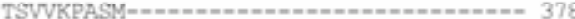

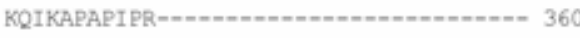

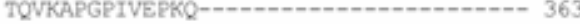

EOVWPPVGLTG-- 374 
When plasmid profiles were hybridized with the nirK probe, which targets an internal part of nirK, a hybridization signal corresponding to the 750 - or $800-\mathrm{kb}$ plasmid (i.e., plasmid $\mathrm{f}$ or g) was observed with all five strains of Sp245 (Fig. 2B). In addition, a second hybridization signal was detected for four Sp245 strains including ours, on plasmid a, b, or e. To ascertain which of the two replicons harbors nirK1, a gene found $6.7 \mathrm{~kb}$ downstream of nirK1 (i.e., carR) in the A. brasilense Sp245 genome sequencing project was used as a probe. This regulatory gene is involved in global control of carbohydrate catabolism in A. brasilense (Chattopadhyay et al. 1994). Only one hybridization signal was observed, corresponding to one of the 750- or 800-kb plasmids (data not shown).

\section{Comparative analysis of nirK flanking sequences in A. brasilense Sp245.}

In our strain of $A$. brasilense $\mathrm{Sp} 245$, the region upstream of nirK1 and nirK2 differed. Indeed, analysis of 861 bp upstream of the start codon revealed low identity $(36.6 \%)$ between the two promoter regions and their upstream genetic environments. In the case of nirK1, an open reading frame (ORF) transcribed in the same direction could be identified 1,093 bp upstream (Fig. 3A). The deduced protein sequence of 96 amino acids in length $(10.45 \mathrm{kDa})$ presented significant homology with sequences of oxidoreductase NAD-binding domains found in globins, the highest identity (64\%) being obtained with Methylobacterium sp. strain 4-46 (GenBank accession number ZP_01846193). The analysis of a bigger region surrounding nirK1 in the $A$. brasilense Sp245 genome sequencing project indicated that nirKl is not part of an operon.

Upstream of nirK2 and in opposite orientation, two putative ORF displaying similarities to genes involved in denitrification could be identified (Fig. 3B). The deduced protein sequence of the first ORF beginning 496 bp upstream from nirK2 was found to be 150 amino acids long (molecular mass of 16.87 $\mathrm{kDa}$ ). It showed significant homology with small subunit precursors NorC (cytochrome $\mathrm{c}$ subunit) of nitric oxide reductases, the highest identity $(81 \%)$ being obtained with the $\alpha$ proteobacterium Rhizobium sp. strainG-179 (GenBank accession number AAC79450; mistakenly identified as a pseudomonad until now). The second ORF was found $14 \mathrm{bp}$ upstream of norC in the same orientation (Fig. 3B). The deduced protein sequence of this ORF (363 amino acids long, molecular mass of $40.35 \mathrm{kDa}$ ) displayed significant homology with large subunit precursors NorB (cytochrome b subunit) of nitric oxide reductase, the highest identity $(69 \%)$ being obtained with the $\alpha$-proteobacterium Magnetospirillum gryphiswaldense MSR-1 (GenBank accession number CAM75374). Eight transmembrane helices were predicted for NorB.

\section{Comparison of nirK sequences of A. brasilense Sp245.}

Despite divergent upstream regions between nirK1 and nirK2 in our strain of $A$. brasilense Sp245, promoter analysis revealed several common features for nirK1 and nirK2, as follows. In both cases, there were two consecutive TTG and ATG initiation codons in the same frame, upstream of the coding region. The ATG was chosen as the most probable initiation because there is a potential ribosome binding site (RBS) close by. Along with a predictive transcription start at a relevant location, further analysis revealed consensus, $\sigma^{70}$-relevant -10 and -35 promoter sequences. Finally, the sequence wyTTGAC- $\left(\mathrm{N}_{4}\right)$-GTCAArw, which is a recognition motif for the fumarate-nitrate reduction (FNR) transcriptional activator and is present in other nirK promoters, also was shown upstream of the two genes.

In our strain of $A$. brasilense Sp245, the nirK1 and nirK2 ORF were 1,066 bp long and have a $\mathrm{G}+\mathrm{C}$ content of 64 and $63 \%$, respectively. They shared $96 \%$ identity at the DNA level, with discrepancies at 41 positions located over the entire sequence.

The deduced NirK1 and NirK2 sequences corresponded to polypeptides of 354 amino acid residues sharing $99.2 \%$ identity (99.4\% similarity), because many mutations were silent (Fig. 4), with a molecular mass of $37.7 \mathrm{kDa}$ (unprocessed precursor). Typical of periplasmic metalloenzymes, the NirK1 and NirK2 products displayed a signal peptide at the $N$-terminal end (very high probability of $P=0.999$ in both cases) and a putative cleavage site between the 26th and 27th residues (probability of $P=0.601$ in both cases). The deduced sequences for nirK1 and nirK2 presented significant homology with those of other copper-type nitrite reductases, the best 'expect' value being obtained with Hyphomicrobium denitrificans A3151 (GenBank accession number BAC00912), with 59\% identity in both cases.

When the two deduced NirK protein sequences were aligned with those of other copper-containing dissimilatory nitrite reductase (NirK) orthologs, the high degree of amino acid identity among the NirK sequences (excluding the signal peptide sequences) was striking (Fig. 4). Generally, copper-containing nitrite reductases fold in a trimeric structure in which a monomer (approximately $37 \mathrm{kDa}$ ) contains two copper atoms. One of these is designated type 1 and is required for electron transfer. The other center is designated type 2 and is the site of nitrite binding and reduction. On the basis of the alignments, type 1 and type 2 copper ligands are conserved in the deduced amino acid sequence of both NirK1 and NirK2: $\mathrm{H}_{118}, \mathrm{C}_{159}, \mathrm{H}_{167}$, and $\mathrm{M}_{172}$ are ligands to the type 1 center whereas $\mathrm{H}_{123}, \mathrm{H}_{158}$, and $\mathrm{H}_{314}$ are ligands to the type 2 center (A. brasilense numbering) (Zumft 1997). Similarly, the active sites $\mathrm{D}_{121}$ and $\mathrm{H}_{263}(A$. brasilense numbering), which are required for $\mathrm{NO}_{2}^{-}$reducing activity, are conserved in both genes (Zumft 1997). These observations further confirm that the genes identified in A. brasilense Sp245 encode members of the NirK family of coppercontaining dissimilatory nitrite reductases.

\section{Phylogenetic analyses of nirK genes in $A$. brasilense Sp245 and other bacteria.}

Neighbor-joining (NJ) phylogenetic trees were generated for nirK (data not shown) and for NirK (Fig. 5) after alignment of 66 eubacterial and archaeal sequences. These trees revealed that NirK1 and NirK2 clustered next to most $\beta$-proteobacterial

Fig. 4. Alignment of NirK1 and NirK2 deduced protein sequences from Azospirillum brasilense Sp245 with those of common copper-containing dissimilatory nitrite reductase nirK orthologues. Identical residues are indicated by white letters in black background; similar residues conserved in $60 \%$ of the sequences are indicated by black letters in gray background. The type 1 and type 2 copper ligands are indicated by 1 and 2 , respectively. The black arrows indicate amino acid residues involved in a hydrogen-bond network around the type 2 copper and playing a role in proton donation to the substrate. Putative proteolytic cleavage site for removal of the signal peptide from NirK1 and NirK2 is indicated by scissors. NirK1 and NirK2 sequences are identical, with the exception of different residues at positions 277 and 182 and similar residues at positions 115 (A. brasilense numbering). Sequences from top to bottom were from A. brasilense Sp245 NirK1 (A.brasil1) and NirK2 (A.brasil2), Hyphomicrobium denitrificans A3151 (H.denitri, accession number BAC00912), Nitrosospira multiformis ATCC 25196 (N.multifo, YP_412685), Neisseria gonorrhoeae FA 1090 (N.gonorrh, AAW89933), Alcaligenes faecalis S-6 (A.faecali, P38501), Rhizobium sullae HCNT1 (R.sullae, Q60214), Achromobacter cycloclastes IAM 1013 (A.cyclocl, AAB19386), A. xylosoxidans GIFU1051 (A.xylosox, BAA33678), Pseudomonas chlororaphis ATCC 13985 (P.chloror, CAA79939), and Rhodobacter sphaeroides 2.4.3 (R.sphaero, AAB05767). 


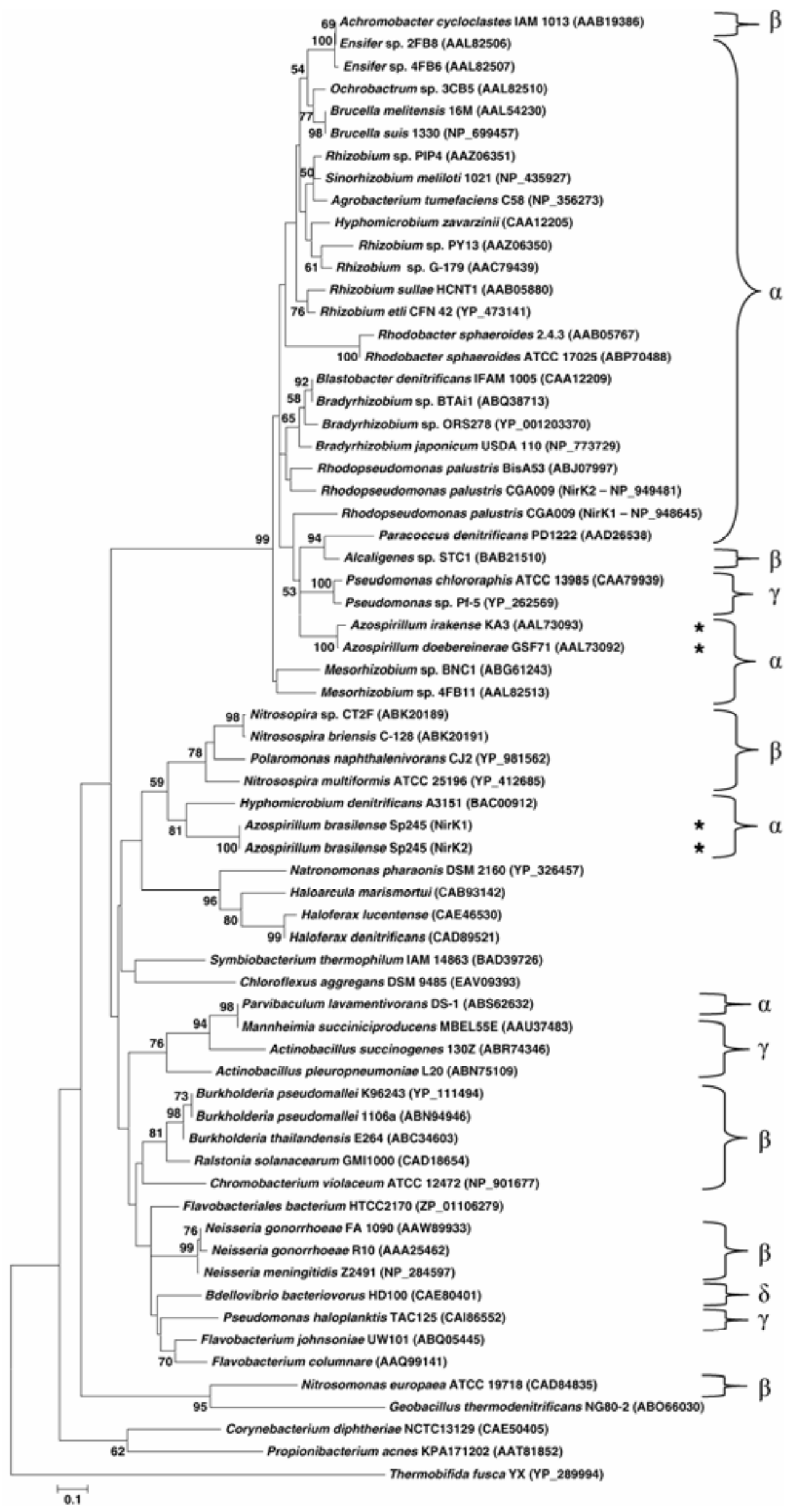

836 / Molecular Plant-Microbe Interactions 
sequences rather than in the vicinity of the two other NirK Azospirillum sequences available and most $\alpha$-proteobacterial sequences, regardless of whether DNA (data not shown) or deduced protein sequences (Fig. 5) were used. The only other $\alpha$ proteobacterial sequence close to those of $A$. brasilense $\mathrm{Sp} 245$ was that of $H$. denitrificans A3151, which was in a neighboring subcluster. Similar findings also were found for trees generated by maximum parsimony (MP) and maximum likelihood (ML) methods (data not shown). These results point to past horizontal gene transfers from $\beta$-proteobacteria to $\alpha$-proteobacteria, such as A. brasilense Sp245.

When estimating the numbers of nonsynonymous substitutions per site $(\mathrm{dN})$ and synonymous substitutions per site (dS) for nirK, using the Kumar method under MEGA, it appears that $\mathrm{dN}(0.748 \pm 0.038)$ was equivalent to $\mathrm{dS}(0.732 \pm 0.044)$. This finding points to neutral selection for nirK in bacteria.

\section{Functionality of the two nirK genes in A. brasilense Sp245.}

Because the promoter regions of nirK1 and nirK2 differ, they were cloned from our strain of $A$. brasilense Sp245, each as a DNA fragment approximately $800 \mathrm{bp}$ in size, and fused to egfp in plasmid pOT1e to obtain transcriptional fusions. Under in vitro conditions, the expression levels of PnirK1-egfp and PnirK2-egfp were low under fully aerobic conditions; under microaerobic conditions (i.e., tubes entirely filled with medium), the increase in fluorescence was 8.6-fold for PnirK1egfp and 7.3-fold for PnirK2-egfp (Fig. 6A and B). Moreover, the expression of PnirK2-egfp could be induced by $5 \mathrm{mM}$ of nitrate or nitrite under microaerobiosis (data not shown), which are conditions known to trigger the transcription of nirKl (Pothier et al. 2007).

Inactivation of nirK coding sequence was carried out by single homologous recombination using the pKNOCK tool. In the
Sp245 strain from Knoxville, which bears only nirK1, the mutant obtained grew slowly under denitrifying conditions but could no longer reduce $\mathrm{NO}_{2}{ }^{-}$based on the Griess-Ilosvays reaction (data not shown). In our Sp245 strain, a nirK1 mutant and a nirK2 mutant were obtained, but development of a nirK1 nirK2 double mutant failed. The two mutants still could denitrify, because i) they still were able to consume $\mathrm{NO}_{2}{ }^{-}$and ii) there was $\mathrm{N}_{2} \mathrm{O}$ accumulation in the headspace when acetylene was used to block the $\mathrm{N}_{2} \mathrm{O}$ reductase (data not shown). These results demonstrate that both nirK1 and nirK2 are functional and that the presence of a single nirK gene is sufficient for denitrification in A. brasilense Sp245.

\section{Activity of nirK genes in planta.}

When a rifampicin-resistant derivative of $A$. brasilense Sp245 (i.e., Sp245-Rif) harboring either the PnirK1-egfp or the PnirK2-egfp transcriptional fusion was inoculated singly onto spring wheat (cv. Fiorina) seedlings under gnotobiotic conditions (Pothier et al. 2007), microscopy observations at 7 days revealed that inoculant cells were fluorescent on roots. Fluorescence was found in both single cells and numerous sparse clumps of cells, which were located especially in the root hair zone (Fig. 7A and D). The two fusions also were expressed on roots i) when winter wheat (cv. Soissons) was used instead of spring wheat or ii) when analysis was done at 10 days instead of 7 days (not shown). Therefore, it appears that both nirK genes are upregulated when A. brasilense Sp245 colonizes wheat roots.

\section{DISCUSSION}

In this study, dissimilatory nitrite reduction in A. brasilense Sp245 was shown to be catalyzed by two functional NirK iso-

Fig. 5. Neighbor-joining phylogenetic tree based on partial NirK sequences (accession numbers in parenthesis). The tree was inferred using the Kimura-2 parameter; bootstrap values (1,000 replicates) are shown when above 50\%, and the scale bar represents the percentage of substitutions per site. The deduced protein sequence of nirK from Thermobifida fusca YX was used as outgroup. Symbols $\alpha, \beta$, and $\gamma$ indicate the corresponding proteobacterial subdivisions, and sequences from Azospirillum are shown using asterisks.
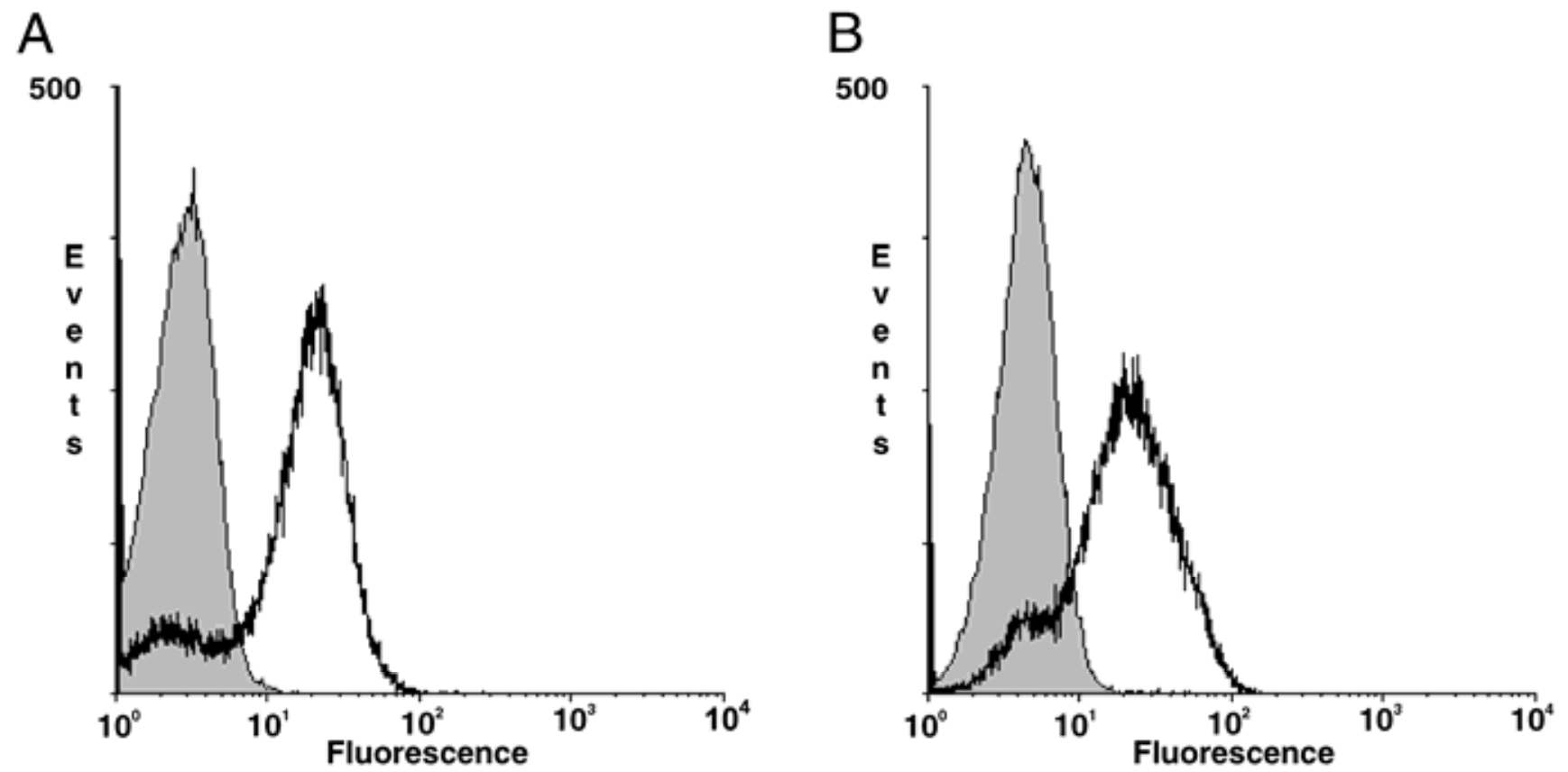

Fig. 6. Flow cytometry analysis of nirK transcriptional fusions. Relative intensity of green fluorescence (FL1-H) during flow-cytometry analysis of A, the PnirK1egfp transcription fusion Azospirillum brasilense Sp245-Rif(pR3.8) and B, the PnirK2-egfp transcription fusion A. brasilense Sp245-Rif(pR3.9) grown in ABmal medium under aerobic (gray area; control) or microaerobic conditions (solid line). Representative results for one of three replicates are shown. 
enzymes that are plasmid encoded. For the various species studied so far, the genes implicated in the denitrification process can be found either tightly clustered on the chromosome or plasmid-borne, even in the case of nirK (Chan and McCormick 2004; Schwintner et al. 1998).

A. brasilense $\mathrm{Sp} 245$ is the third example of a bacterium possessing two isofunctional nitrite reductases. Indeed, this already was reported for Thauera spp., a $\beta$-proteobacterium isolated from a high-nitrate-removal-rate reactor (Etchebehere and Tiedje 2005), and in the $\alpha$-proteobacterium Rhodopseudomonas palustris (Larimer et al. 2004). In Thauera spp., however, the two nirS paralogs clustered distantly from one another, suggesting that one had been acquired horizontally. In contrast, here, NirK1 and NirK2 clustered similarly (as in Rhodopseudomonas spp.) and displayed high identity (99.2\%). Phylogenetic analyses showed that both differed from most other $\alpha$-proteobacterial NirK sequences, including that of other Azospirillum strains (Kloos et al. 2001). Therefore, it appears that horizontal acquisition of nirK by $A$. brasilense Sp245 (probably from a $\beta$ proteobacterium) took place prior to a gene duplication event. Indeed, nirK seems prone to horizontal transfer, especially in comparison with the nitrite reductase-encoding gene nirS (Heylen et al. 2006). The $\mathrm{G}+\mathrm{C}$ content of nirK1 and nirK2 (64 and 63\%, respectively) are in the range expected for Azospirillum spp.

Regions flanking nirK1 and nirK2 paralogs are different. Genes encoding homologues of small- and large-subunit precursors of nitric oxide reductase (i.e., NorC and NorB) were identified upstream of nirK 2 , and these genes displayed typical $\alpha$-proteobacterial phylogenetic features (not shown). The proximity of nirK with nor genes also is documented in denitrifying $\alpha$-proteobacteria such as Brucella and Sinorhizobium spp. (Philippot 2002), whose nirK sequences were found in the large $\alpha$-proteobacterial cluster (Fig. 5). On this basis, it is tempting to speculate that once nirK was acquired horizontally by $A$. brasilense $\mathrm{Sp} 245$ from $\beta$-proteobacteria, it recombined with an earlier $\alpha$-proteobacterial nirK allele adjacent to the norB-nor $C$ genes (i.e., the current nirK 2 organization). If so, the nirK duplication event would have taken place afterward.

Unlike for nirK2, nor genes are not present upstream of nirK1. Instead, an ORF was found of which part of the deduced protein sequence corresponded to an oxidoreductase NADbinding domain present in globins. In the case of globins, the enzyme may have NO dioxygenase activity, which is required for maintenance of a low, nontoxic NO concentration in the cell (Poole and Hughes 2000). However, it is not possible from the Sp245 sequence alone to establish that the neighboring gene encodes a globin oxidoreductase. Therefore, it cannot be concluded that genes next to nirKl are involved in denitrification, such as the ones next to nirK2.

Transcriptional fusions indicated that both nirK1 and nirK2 promoter regions of $A$. brasilense $\mathrm{Sp} 245$ were upregulated in vitro under conditions favorable for denitrification, as well as during colonization of spring wheat roots (under experimental conditions where nirK 1 is not expressed if the plant is replaced by polyvinylidene fluoride inert material) (Pothier et al. 2007). Thus, the two genes display similarity in their expression patterns despite divergent promoter regions, a result contrasting with the different regulation of dual nirS genes in Thauera spp. (Etchebehere and Tiedje 2005). This could imply (Zhang 2003) that the duplication event in A. brasilense Sp245 was rather recent in evolutionary terms and that functional diver-
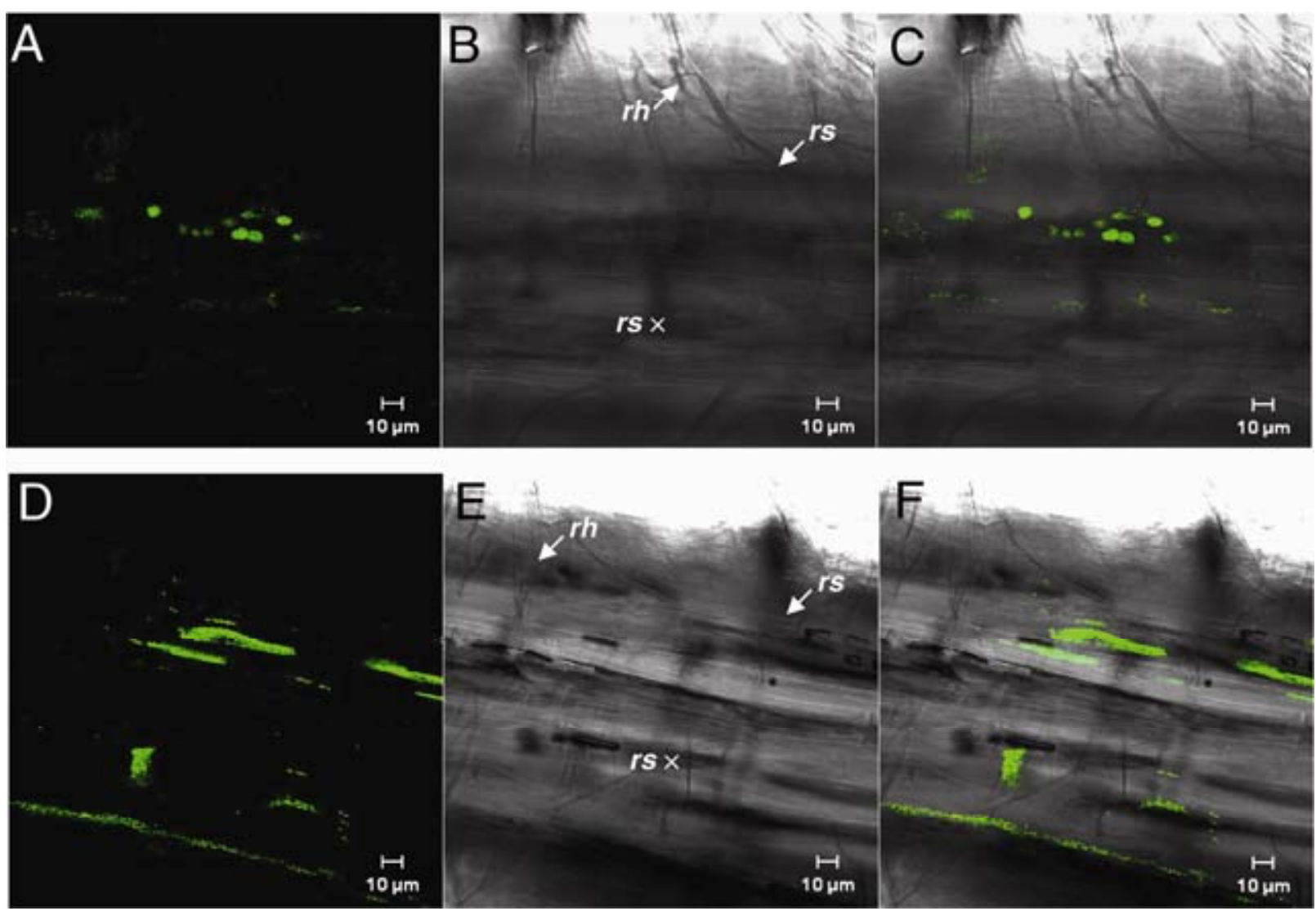

Fig. 7. In planta expression of nirK transcriptional fusions analysed by a confocal laser scanning microscope. Expression of A, the PnirK1-egfp transcription fusion Azospirillum brasilense Sp245-Rif(pR3.8) and D, the PnirK2-egfp transcription fusion in A. brasilense Sp245-Rif(pR3.9) was monitored in the root hair zone of spring wheat roots at 7 days after inoculation of seedlings (fluorescent emission analysis). B and $\mathbf{E}$, Images of the root obtained in transmitted light. C, Overlay of A and B and F, overlay of D and E; $r s=$ root surface and $r h=$ root hair. 
gence has not yet proceeded extensively. Indeed, by mutating nirK1 or nirK2, it appeared that the presence of either nirK1 or nirK2 was sufficient for maintaining denitrification in A. brasilense Sp245. In the Sp245 strain from Knoxville, inactivation of the sole nirK gene (i.e., nirKl) abolished denitrification but did not completely prevent growth, showing that cells lacking NirK activity still are viable and able to grow slightly under denitrifying conditions, a result already documented in other taxa (Baek and Shapleigh 2005; Philippot et al. 1995; Rees et al. 1997).

When assessing all bacterial sequences together, it appears that nirK has been subjected to neutral selection, which means that there is a low level of selective constraint on nirK diversification. Previous clustering of nirK clone sequences revealed some relations with the type of environment from which the sequences were obtained (Braker et al. 2000; Heylen et al. 2006; Priemé et al. 2002; Sharma et al. 2005). Perhaps this reflects the importance of physical proximity for horizontal gene transfer (Heylen et al. 2006). This also might be significant in terms of the particularity of denitrification processes in different environments. In the case of A. brasilense Sp245, the presence of two active nitrite reductases might be advantageous for root colonization, because environmental conditions in the rhizosphere are propitious for denitrification (Binnerup and Sørensen 1992; Højberg et al. 1999). Indeed, denitrification enables the bacterium to maintain energy metabolism when confronted with oxygen-deprived rhizosphere conditions (Philippot et al. 1995). In addition, NO produced by denitrifiers also may affect competing bacteria such as Bacillus subtilis, by causing stress and growth inhibition (Choi et al. 2006), and perhaps also dispersal of biofilm formed by neighboring bacteria such as pseudomonads (Barraud et al. 2006). Such effects could not be assessed in the current gnotobiotic conditions; however, whether or not they could favor Sp245 in its competition for root colonization sites deserves further attention.

Implication of NO in the plant hormone signaling network, especially in the indole-3-acetic acid biosynthesis pathway, is now widely documented (Lamattina et al. 2003). The promotion of lateral root formation of tomato inoculated by A. brasilense $\mathrm{Sp} 245$ previously was shown to require NO; however, whether the plant benefited directly from the NO produced by bacteria or whether the association could modify NO production by root cells remains to be established (Creus et al. 2005). Nitric oxide also was produced during the Medicago spp.-Sinorhizobium meliloti interaction, raising the hypothesis of a role for NO in symbiosis signaling (Baudouin et al. 2006; Pii et al. 2007).

By analyzing the plasmid profile of Sp245 strains obtained from different laboratories, genomic rearrangements likely to have affected the smallest replicon (previously called the 75MDa plasmid by Vieille and associates [1989]) (i.e., plasmid b on Fig. 2A) were revealed. Based on the principle of parsimony and the comparison of plasmid sizes, the most likely scenario of plasmid rearrangements is that replicon $b$ (present in the Sp245 strains from Rehovot and Leuven; Fig. 2A, lane 5) could i) undergo a deletion event but without losing nirK (resulting in plasmid a in the Sp245 strain from Paris; Fig. 2A, lane 4), ii) form a cointegrate with the $160-\mathrm{kb}$ replicon $\mathrm{d}$ (resulting in the nirK plasmid e in our Sp245 strain; Fig. 2A, lanes 2), or iii) be lost (in the Sp245 strain from Knoxville) (i.e., the one used in the current genome sequencing project; Fig. 2A, lane 3). Indeed, the presence of a single nirK copy in the latter, corresponding to nirKl according to its promoter region sequence, was confirmed by Southern hybridization (data not shown) and by searching nirK in the draft genome sequence of Sp245 (not available at the onset of this study). In summary, one of the plasmids bearing nirK can experience major genomic rearrangements. These rearrangements might be accompanied by the disappearance of genetic material, as can be suspected when assessing Eckhardt gels, which provides a likely explanation for the lack of a nirK2 sequence in the A. brasilense Sp245 genome sequencing project. However, because the history of strain exchange patterns of Sp245 between these different laboratories has not been kept, the aforementioned scenario of rearrangements is only putative. Plasmid rearrangements have been described previously for $\mathrm{Sp} 245$, such as the loss of plasmid b (Vieille et al. 1989) or modification of plasmid profile after introduction of a RP4 replicon and longterm storage in rich medium (Katzy et al. 1998). Genomic rearrangements, such as plasmid loss or formation of cointegrate, also have been described in several Azospirillum strains undergoing phenotypic switch (Vial et al. 2006). In A. lipoferum 4B,

Table 2. Bacterial strains and plasmids used in this study

\begin{tabular}{|c|c|c|}
\hline Strains and plasmids & Description $^{\mathrm{a}}$ & Reference or source \\
\hline \multicolumn{3}{|l|}{ Strains } \\
\hline Azospirillum brasilense Sp245 & Strain isolated from roots of wheat (Brazil) and kept in Lyon & Baldani et al. 1983 \\
\hline A. brasilense Sp245-Rif & Root-proficient, spontaneous rifampicin-resistant mutant of Sp245 & Pothier et al. 2007 \\
\hline Sp245nirK1 & nirK1 mutant of Sp245; $\mathrm{Km}^{\mathrm{r}}$ & This study \\
\hline Sp245nirK2 & nirK2 mutant of $\mathrm{Sp} 245 ; \mathrm{Km}^{\mathrm{r}}$ & This study \\
\hline Rhizobium etli CFN42 & Strain used as marker for plasmid profiles & Romero et al. 1991 \\
\hline \multicolumn{3}{|l|}{ Plasmids } \\
\hline pGEM-T easy & Cloning vector for polymerase chain reaction products & Promega \\
\hline pKNOCK-Km & Mobilizable plasmid, suicide vector for A. brasilense; $\mathrm{Km}^{\mathrm{r}}$ & Alexeyev 1999 \\
\hline pOT1e & $\begin{array}{l}\text { Promoter probe vector based on pBBR1-MCS- } 5 \text { replicon; contains promoterless } e g f p \text { and MCS } \\
\text { between two transcriptional terminators; } \mathrm{Gm}^{\mathrm{r}}\end{array}$ & Allaway et al. 2001 \\
\hline $\mathrm{pR} 2.54$ & PnirK1-egfp transcription fusion in pOT1e; $\mathrm{Gm}^{\mathrm{r}}$ & Pothier et al. 2007 \\
\hline pR2.62 to $\mathrm{pR} 2.66$ & Cosmid pWEB carrying nirK1 from A. brasilense Sp245 & This study \\
\hline pR2.67 & Cosmid pWEB carrying nirK2 from A. brasilense Sp245 & This study \\
\hline pR3.6 & $\begin{array}{l}\text { 1,183-bp amplicon (F5302/F3906) with } 858 \text { bp upstream of the nirK1 ATG start codon cloned } \\
\text { in pGEM-T easy; Ap }\end{array}$ & This study \\
\hline $\mathrm{pR} 3.7$ & $\begin{array}{l}\text { 1,139-bp amplicon (F5303/F3906) with } 814 \text { bp upstream of the nirK2 ATG start codon cloned } \\
\text { in pGEM-T easy; Ap }\end{array}$ & This study \\
\hline pR3.8 & $\begin{array}{l}\text { PnirK1-egfp transcription fusion in pOT1e, 966-bp ClaI/SalI fragment from pR3.6 with } 848 \text { bp } \\
\text { upstream of the nirK1 ATG start codon cloned in ClaI/SalI-digested pOT1e; Gm }{ }^{\mathrm{r}}\end{array}$ & This study \\
\hline $\mathrm{pR} 3.9$ & $\begin{array}{l}\text { PnirK2-egfp transcription fusion in pOT1e, 920-bp ClaI/SalI fragment from pR3.7 with } 802 \mathrm{bp} \\
\text { upstream of the nirK2 ATG start codon cloned in ClaI/SalI-digested pOT1e; } \mathrm{Gm}^{\mathrm{r}}\end{array}$ & This study \\
\hline $\mathrm{pR} 3.10$ & 268-bp internal amplicon of $\operatorname{nirK}$ (F5635/F5636) cloned in pGEM-T easy; Ap ${ }^{\mathrm{r}}$ & This study \\
\hline pR3.12 & 290-bp NotI fragment from pR3.10 cloned in NotI-digested pKNOCK-Km & This study \\
\hline
\end{tabular}

${ }^{\mathrm{a}} \mathrm{Km}^{\mathrm{r}}, \mathrm{Gm}^{\mathrm{r}}$, and $\mathrm{Ap}^{\mathrm{r}}=$ resistant to kanamycin, gentamycin, and ampicillin, respectively. 
the appearance of nonswimming variants was correlated with the loss of a 750-kb plasmid, that plasmid bearing the acdS gene whose product allows deamination of the ethylene precursor 1-aminocyclopropane-1-carboxylate (Prigent-Combaret et al. in press). Thus, genome plasticity of Azospirillum strains may lead to the loss of genetic determinants such as acdS or nirK, which encode products that can be involved in the plant growth-promoting effect of Azospirillum spp.

\section{MATERIALS AND METHODS}

\section{Bacterial strains and media.}

Bacterial strains and plasmids used in this study are listed in Table 2. A. brasilense was grown at $28^{\circ} \mathrm{C}$ in Luria-Bertani (LB) medium (Sambrook et al. 1989) with $\mathrm{NaCl}$ at only $5 \mathrm{~g} \mathrm{liter}^{-1}$ (i.e., $\mathrm{LBm}$ ), or in $\mathrm{AB}$ medium after replacing glucose with malic acid (5 g liter ${ }^{-1}$; Sigma-Aldrich, Saint Quentin Fallavier, France) as sole carbon source (i.e., ABmal) (Chilton et al. 1974). Escherichia coli was grown in LB medium at $37^{\circ} \mathrm{C}$. Rhizobium etli CFN42 was grown in tryptone-yeast extract medium supplemented with $6 \mathrm{mM} \mathrm{CaCl}_{2}$. Liquid cultures were incubated on a rotary shaker at $180 \mathrm{rpm}$ (50 rpm for microtitration plates). One-third of the volume of the tubes was filled to ensure fully aerobic conditions. To implement oxygen-limited conditions (microaerobiosis), the tubes were filled entirely with medium. Anaerobic growth was performed in 150-ml plasma flasks containing $38 \mathrm{ml}$ of LBm medium supplemented with $\mathrm{NaNO}_{2}$ to a final concentration of $2 \mathrm{mM}$. Anaerobiosis was obtained by using a vacuum pump and flushing with helium (three times). Plasma flasks then were inoculated with 2 $\mathrm{ml}$ of an aerobic overnight culture. Antibiotics (Euromedex, Souffelweyersheim, France) were added at the following final concentrations, unless otherwise specified: ampicillin (Ap) at $100 \mu \mathrm{g} \mathrm{ml}^{-1}$, gentamycin $(\mathrm{Gm})$ at $25 \mu \mathrm{g} \mathrm{ml}^{-1}$, $\operatorname{kanamycin}(\mathrm{Km})$ at $40 \mu \mathrm{g} \mathrm{ml}^{-1}$, and rifampicin (Rif) at $50 \mu \mathrm{g} \mathrm{ml}^{-1}$.

\section{Plasmid transfer and PCR conditions.}

Bacterial conjugations were performed by biparental mating. To this end, 500- $\mu$ l cell suspensions of A. brasilense Sp245Rif recipient cells grown overnight in LBm containing Ap and $500 \mu \mathrm{l}$ of $E$. coli S17.1 donor cells grown overnight in LB containing $\mathrm{Gm}$ or $\mathrm{Km}$ were mixed and collected by centrifugation. Cell pellets then were resuspended in $100 \mu \mathrm{l}$ of $\mathrm{LBm}$, placed onto LBm agar, and incubated for $20 \mathrm{~h}$ at $28^{\circ} \mathrm{C}$. Cells were resuspended in $1 \mathrm{ml}$ of $10 \mathrm{mM} \mathrm{MgSO}_{4}$ and transconjugants were selected on LBm or ABmal containing Ap, Rif, and Gm (for pR3.8 or pR3.9) or Km (for pR3.12).

PCR primers (synthesized by Invitrogen, Cergy-Pontoise, France) are listed in Table 1. PCR amplifications were performed according to the Taq polymerase manufacturer (Invitrogen) in $25 \mu \mathrm{l} \mathrm{using} 50 \mathrm{ng}$ of template DNA or using $1 \mu \mathrm{l}$ of $E$. coli cells for library screening. The amplification cycle consisted of an initial $5 \mathrm{~min}$ at $95^{\circ} \mathrm{C} ; 35$ cycles of $30 \mathrm{~s}$ at $95^{\circ} \mathrm{C}, 30 \mathrm{~s}$ at annealing temperature, and $30 \mathrm{~s}$ (or $90 \mathrm{~s}$ for large amplicons) at $72^{\circ} \mathrm{C}$; followed by a final 7 -min extension at $72^{\circ} \mathrm{C}$. When used as probes and for sequencing, PCR products were purified using QIAquick PCR purification (Qiagen, Courtaboeuf, France).

\section{Plasmid profiles and Southern hybridizations.}

Plasmid profiles were determined by a modified Eckhardt agarose gel electrophoresis technique, as described (Vial et al. 2006), using Azospirillum cells grown in ABmal medium and electrophoresis at $50 \mathrm{~V}$ for $24 \mathrm{~h}$. R. etli CFN42 was used as marker for estimation of plasmid size. For Southern hybridization experiments, genomic and cosmid DNA digested with either BamHI, EcoRI, PvuII, or SalI, or plasmids, were blotted to GeneScreen Plus nylon membrane (Perkin-Elmer, Zaventem, Belgium) with a vacuum blotter (Bio-Rad Laboratories, Marnesla-Coquette, France). DNA was fixed by exposing to a 312-nm transilluminator for $4 \mathrm{~min}$. Prehybridization, labeling, and purification of probes as well as hybridization were performed as previously described (Vial et al. 2006).

\section{Sequencing and sequence analysis.}

Sequencing was performed by Genome Express (Meylan, France) and sequences were analyzed with BLASTN and BLASTX algorithms on the National Center for Biotechnology Information website (Altschul et al. 1997). Identification of ORF and conversion to protein sequences were done with CUPlot v1.0 using the Azospirillum codon usage database. Prediction of promoters was done with BPROM (SoftBerry, Mount Kisco, NY, U.S.A.) and manual refining then was implemented. Inverted repeat sequences near or within the predicted promoter regions were identified and examined for similarity to known binding motifs for transcriptional regulators of denitrification genes using the program FUZZNUC. Transcription starts were predicted using prokaryote neural network promoter prediction v2.2. Signal peptide and cleavage sites were predicted using SignalP v3.0 whereas transmembrane helices were detected with TMHMM v2.0.

DNA sequences and deduced protein sequences were aligned using the multiple alignment software CLUSTAL X v1.83. Between 141 and 913 amino acids were used for phylogenetic analyses using the software package MEGA v4 (Molecular Evolutionary Genetics Analysis). Phylogenetic distances were calculated by the NJ method using the Jukes-Cantor parameter model for DNA and Poisson correction for protein in MEGA. Consensus NJ trees were evaluated by bootstrap analyses based on 1,000 resamplings of each data set.

Accession numbers for sequence data obtained in the current work are EU221420 and EU221421. Preliminary data of the $A$. brasilense Sp245 genome sequencing project were used to confirm sequencing or ORF prediction. Additional NirK sequences from archaea and bacteria were obtained from the National Center for Biotechnology Information databases.

\section{Determination of nirK1 and nirK2 sequences.}

Total genomic DNA of $A$. brasilense Sp245 was obtained as described (Sambrook et al. 1989). A genomic library of $A$. brasilense $\mathrm{Sp} 245$ was constructed in E. coli Epi-100 $\mathrm{T} 1^{\mathrm{R}}$ using a pWEB cosmid-cloning kit (Epicentre, Madison, WI, U.S.A.) according to the manufacturer's instructions, except that sonication was performed for $1 \mathrm{~min}$ using an S-line apparatus (Bioblock, Illkirch, France) to shear genomic DNA. The 650 colonies obtained were transferred individually to microtitration wells and screened by PCR using primers F3787/F3789 or F3905/F3906 (Table 1). Sequencing of DNA of interest was performed by genome walking.

\section{Construction of $e g f p$ transcriptional fusions with nirK1 and nirK 2 promoters.}

All standard cloning steps were carried out as described previously (Sambrook et al. 1989). Restriction enzymes were supplied by Fermentas (Burlington, Canada). The PnirK1-egfp and PnirK2-egfp transcription fusions were constructed by PCR amplification of PnirK1 (1,183-bp amplicon, of which 858 bp were upstream of the nirK1 start codon) and PnirK2 (1,139-bp amplicon, of which $814 \mathrm{bp}$ were upstream of the nirK2 start codon), and subcloning into pGEM-T easy (Promega, Charbonnières, France). Each of the PCR primers targeting the promoter regions of nirK1 and nirK2 (F5302 and F5303 respectively) (Table 1) used to this end introduced a ClaI restriction site and were used in combination with F3906 
targeting nirK. White colonies were screened by PCR with primers F3906 (Table 1) and M13rev for correct orientation in pGEM-T easy (sense strand of lacZ). These constructs resulting in pR3.6 and pR3.7 (for PnirK1 and PnirK2, respectively) were digested with $\mathrm{ClaI}$ and SalI, cloned into the ClaI/SalIdigested plasmid pOT1e and transferred into chemically competent cells of E. coli S17.1 $\lambda$ pir (Sambrook et al. 1989). The resulting constructs, pR3.8 for PnirK1 and pR3.9 for PnirK2, carry 848 and $802 \mathrm{bp}$, respectively, upstream of the start codon and both contain $118 \mathrm{bp}$ of the coding region, which was confirmed by sequencing with primers F2603 and F2604 (Table 1). These constructs were introduced into A. brasilense $\mathrm{Sp} 245$ Rif by biparental mating (as described above).

\section{Construction of nirK1 and nirK2 mutants.}

To construct nirK1 and nirK2 mutants, a 268-bp nirK internal fragment was amplified by PCR with primers F5635/F5636 (Table 1) and subcloned into pGEM-T easy (Promega). White colonies were screened by PCR with primers F5635/F5636 for correct insertion in pGEM-T easy, resulting in pR3.10. The insert of plasmid pR3.10 was digested with Not I and cloned into the NotI site of pKNOCK-Km (Alexeyev 1999), resulting in pR3.12 after transfer into chemically-competent cells of $E$. coli S17.1 $\lambda$ pir (Sambrook et al. 1989). For validation of the correct insertion of nirK upstream of the Km-resistance cassette in pR3.12, sequencing using primer F5595 was performed before introduction into A. brasilense Sp245-Rif and the Sp245 strain from Knoxville by biparental mating (as described above). Transconjugants resulting from a single recombination event of pR3.12 were selected on ABmal containing Rif and $\mathrm{Km}$ (for Sp245-Rif) or Amp and Km (for the Sp245 strain from Knoxville). These transconjugants were screened by PCR with primers F5595/F5597 for nirK1 inactivation and F5595/F5598 for nirK2 inactivation (Table 1). PCR amplicons were sequenced in order to check the recombination events.

\section{Analysis of promoter activity}

by flow cytometry and epifluorescence microscopy.

Flow cytometry was used to measure fluorescence levels of A. brasilense Sp245 cells carrying either pR3.8 (PnirK1-egfp) or pR3.9 (PnirK2-egfp). Flow cytometry was performed with a FACSCalibur apparatus (Becton Dickinson Biosciences, Pont de Claix, France) fitted with a $15-\mathrm{mW}$ argon laser emitting at $488 \mathrm{~nm}$. FACSFlow solution (Becton Dickinson Biosciences) was used as sheath fluid, as previously described (Pothier et al. 2007).

Microscopy observations of cultures were made using an Axioskop 40 epifluorescence microscope (Carl Zeiss S.A.S., Le Pecq, France) with standard phase-contrast lenses. Fluorescent cells were observed with separate illuminations at 450 to 490 $\mathrm{nm}$ and detection with long-pass emission filter LP-520 nm.

\section{Analysis of denitrification ability of nirK mutants.}

Denitrification ability of nirK mutants was tested based on dissimilatory nitrite and nitric oxide reductase activities and compared with those of the wild type. To this end, the two nirK mutants and the wild-type strain were studied with nitrite as sole electron acceptor under anaerobic conditions, as described above. To monitor $\mathrm{NO}$ reduction to $\mathrm{N}_{2} \mathrm{O}$, which accumulated in the headspace of the plasma flasks in the presence of $10 \%$ acetylene, $\mathrm{N}_{2} \mathrm{O}$ was determined by gas chromatography (Agilent Technologies, Massy, France). $\mathrm{N}_{2} \mathrm{O}$ accumulation indicated a NO reductase activity and, hence, a NirK ${ }^{+}$phenotype of the mutant. $\mathrm{NO}_{2}^{-}$consumption was monitored colorimetrically by the Griess-Ilosvays reaction (Merck, Darmstadt, Germany) in culture medium samples. The lack of a red color reaction indicated the absence of $\mathrm{NO}_{2}^{-}$because of its complete reduction and, hence, a NirK ${ }^{+}$phenotype of the mutant. Both assays were carried out after 3 days of incubation. The experiment was done twice with the same results.

\section{Plant tests.}

Spring wheat plant experiments were done as described by Pothier and associates (2007), under conditions where nirKl is not expressed if the plant is replaced with inert material (polyvinylidene fluoride filter membrane). Briefly, Triticum aestivum $\mathrm{L}$. (cv. Fiorina) seedlings were prepared, inoculated with one of the PnirK-egfp transcriptional fusions, and grown axenically in 144$\mathrm{cm}^{2}$ petri dishes containing water agar. The dishes were placed standing for 7 days in a growth chamber (Sanyo MLR350, Loughborugh, U.K.) at $75 \%$ relative humidity with $16 \mathrm{~h}$ of light $\left(63 \mu \mathrm{E} \mathrm{m}^{-2} \mathrm{~s}^{-1}\right)$ at $26^{\circ} \mathrm{C}$ and $8 \mathrm{~h}$ of dark at $18^{\circ} \mathrm{C}$. Root surface observations were performed using a confocal laser scanning microscope (CLSM) (510 Meta microscope; Carl Zeiss S.A.S.) equipped with an argon-krypton laser, detectors, and filter sets for green fluorescence (i.e., $488 \mathrm{~nm}$ for excitation and 510 to $531 \mathrm{~nm}$ for detection). After acquisition of transmitted light (in bright field mode), the two single-color images acquired were overlaid into a single image using LSM software release 3.5 (Carl Zeiss S.A.S.). Each fusion was studied using two $1-\mathrm{cm}$ root pieces taken from the root tip area of two seedlings.

\section{ACKNOWLEDGMENTS}

We thank I. B. Zhulin (The University of Tennessee and Oak Ridge National Laboratory, U.S.A.) for access to preliminary genome sequence data of $A$. brasilense Sp245, which is supported by the United States National Science Foundation grant EF-0412186 to I. B. Zhulin. We are grateful to M. Weiss-Gayet and P. Couble (UMR CNRS 5534 Centre de Génétique Moléculaire et Cellulaire, Université Lyon 1) for access to the flow cytometry, N. Guillaumaud (UMR CNRS 5557 Ecologie Microbienne) for help with denitrification assays, and F. Poly (UMR CNRS 5557 Ecologie Microbienne) for discussion. We thank G. Alexandre (University of Tennessee, Knoxville, U.S.A.), C. Elmerich (Institut Pasteur, Paris), Y. Okon (The Hebrew University, Rehovot, Israel), and J. Vanderleyden (Catholic University, Leuven, Belgium) for sending Sp245 strains. This work was supported by a fellowship from the French Ministère de l'Education Nationale, de la Recherche et des Nouvelles Technologies to J. Pothier and a research grant from IFR 41 Bio-Environnement et Santé. CLSM observations and plant experiment were carried out at the IFR 41 platforms Centre Technologique des Microstructures and Serre, respectively.

\section{LITERATURE CITED}

Alexeyev, M. F. 1999. The pKNOCK series of broad-host-range mobilizable suicide vectors for gene knockout and targeted DNA insertion into the chromosome of gram-negative bacteria. Biotechniques 26:824-828.

Allaway, D., Schofield, N. A., Leonard, M. E., Gilardoni, L., Finan, T. M., and Poole, P. S. 2001. Use of differential fluorescence induction and optical trapping to isolate environmentally induced genes. Environ. Microbiol. 3:397-406.

Altschul, S. F., Madden, T. L., Schaffer, A. A., Zhang, J., Zhang, Z., Miller, W., and Lipman, D. J. 1997. Gapped BLAST and PSI-BLAST: A new generation of protein database search programs. Nucleic Acids Res. 25:3389-3402

Baek, S.-H., and Shapleigh, J. P. 2005. Expression of nitrite and nitric oxide reductases in free-living and plant-associated Agrobacterium tumefaciens C58 cells. Appl. Environ. Microbiol. 71:4427-4436.

Baldani, V. L. D., Baldani, J. I., and Döbereiner, J. 1983. Effects of Azospirillum inoculation on root infection and nitrogen incorporation in wheat. Can. J. Microbiol. 29:924-929.

Bally, R., and Elmerich, C. 2007. Biocontrol of plant diseases by associative and endophytic nitrogen fixing bacteria. Pages 171-190 in: Associative and Endophytic Nitrogen-Fixing Bacteria and Cyanobacterial Associations. C. Elmerich and W. E. Newton, eds. Kluwer Academic Publishers, Dordrecht, The Netherlands.

Barraud, N., Hassett, D. J., Hwang, S. H., Rice, S. A., Kjelleberg, S., and Webb, J. S. 2006. Involvement of nitric oxide in biofilm dispersal of Pseudomonas aeruginosa. J. Bacteriol. 188:7344-7353.

Bashan, Y., and de-Bashan, L. E. 2002. Protection of tomato seedlings against infection by Pseudomonas syringae pv. tomato by using the 
plant growth-promoting bacterium Azospirillum brasilense. Appl. Environ. Microbiol. 68:2637-2643.

Baudouin, E., Pieuchot, L., Engler, G., Pauly, N., and Puppo, A. 2006. Nitric oxide is formed in Medicago truncatula-Sinorhizobium meliloti functional nodules. Mol. Plant-Microbe Interact. 19:970-975.

Binnerup, S. J., and Sørensen, J. 1992. Nitrate and nitrite microgradients in barley rhizosphere as detected by a highly sensitive denitrification bioassay. Appl. Environ. Microbiol. 58:2375-2380.

Blaha, D., Prigent-Combaret, C., Mirza, M. S., and Moënne-Loccoz, Y. 2006. Phylogeny of the 1-aminocyclopropane-1-carboxylic acid deaminase-encoding gene $a c d S$ in phytobeneficial and pathogenic Proteobacteria and relation with strain biogeography. FEMS (Fed. Eur. Microbiol. Soc.) Microbiol. Ecol. 56:455-470.

Braker, G., Zhou, J., Wu, L., Devol, A. H., and Tiedje, J. M. 2000. Nitrite reductase genes (nirK and nirS) as functional markers to investigate diversity of denitrifying bacteria in Pacific northwest marine sediment communities. Appl. Environ. Microbiol. 66:2096-2104.

Chan, Y. K., and McCormick, W. A. 2004. Experimental evidence for plasmid-borne nor-nir genes in Sinorhizobium meliloti JJ1c10. Can. J. Microbiol. 50:657-667.

Chattopadhyay, S., Mukherjee, A., and Ghosh, S. 1994. Molecular cloning and sequencing of an operon, carRS of Azospirillum brasilense, that codes for a novel two-component regulatory system: Demonstration of a positive regulatory role of $c a r R$ for global control of carbohydrate catabolism. J. Bacteriol. 176:7484-7490.

Chilton, M.-D., Currier, T. C., Farrand, S. K., Bendich, A. J., Gordon, M. P., and Nester, E. W. 1974. Agrobacterium tumefaciens DNA and PS8 bacteriophage DNA not detected in crown gall tumors. Proc. Natl. Acad. Sci. U.S.A. 71:3672-3676.

Choi, P. S., Naal, Z., Moore, C., Casado-Rivera, E., Abruna, H. D., Helmann, J. D., and Shapleigh, J. P. 2006. Assessing the impact of denitrifier-produced nitric oxide on other bacteria. Appl. Environ. Microbiol. 72:2200-2205

Costacurta, A., and Vanderleyden, J. 1995. Synthesis of phytohormones by plant-associated bacteria. Crit. Rev. Microbiol. 21:1-18.

Creus, C. M., Graziano, M., Casanovas, E. M., Pereyra, M. A., Simontacchi, M., Puntarulo, S., Barassi, C. A., and Lamattina, L. 2005. Nitric oxide is involved in the Azospirillum brasilense-induced lateral root formation in tomato. Planta 221:297-303.

Dobbelaere, S., Croonenborghs, A., Amber, T., Ptacek, D., Vanderleyden, J., Dutto, P., Labandera-Gonzalez, C., Caballero-Mellado, J., Aguirre, J. F., Kapulnik, Y., Shimon, B., Burdman, S., Kadouri, D., Sarig, S., and Okon, Y. 2001. Responses of agronomically important crops to inoculation with Azospirillum. Aust. J. Plant Physiol. 28:1-9.

Etchebehere, C., and Tiedje, J. 2005. Presence of two different active nirS nitrite reductase genes in a denitrifying Thauera sp. from a high-nitrateremoval-rate reactor. Appl. Environ. Microbiol. 71:5642-5645.

Ghiglione, J.-F., Gourbière, F., Potier, P., Philippot, L., and Lensi, R. 2000. Role of respiratory nitrate reductase in ability of Pseudomonas fluorescens YT101 to colonize the rhizosphere of maize. Appl. Environ. Microbiol. 66:4012-4016.

Heylen, K., Gevers, D., Vanparys, B., Wittebolle, L., Geets, J., Boon, N., and De Vos, P. 2006. The incidence of nirS and nirK and their genetic heterogeneity in cultivated denitrifiers. Environ. Microbiol. 8:2012-2021.

Højberg, O., Schnider, U., Winteler, H. V., Sørensen, J., and Haas, D. 1999. Oxygen-sensing reporter strain of Pseudomonas fluorescens for monitoring the distribution of low-oxygen habitats in soil. Appl. Environ. Microbiol. 65:4085-4093.

Kamneva, A. B., Katzy, E. I., Borisov, I. V., Scheludko, A. V., and Panasenko, V. I. 2001. Complementation analysis of associative bacteria Azospirillum brasilense Sp245 and S27 defective for motility and flagellation. Russ. J. Genet. 37:135-140.

Katzy, E. I., Matora, L. Y., Serebrennikova, O. B., and Scheludko, A. V. 1998. Involvement of a 120-MDa plasmid of Azospirillum brasilense Sp245 in the production of lipopolysaccharides. Plasmid 40:73-83.

Kloos, K., Mergel, A., Rosch, C., and Bothe, H. 2001. Denitrification within the genus Azospirillum and other associative bacteria. Aust. J. Plant Physiol. 28:991-998.

Lamattina, L., Garcia-Mata, C., Graziano, M., and Pagnussat, G. 2003. Nitric oxide: The versatility of an extensive signal molecule. Annu. Rev. Plant Biol. 54:109-136.

Larimer, F. W., Chain, P., Hauser, L., Lamerdin, J., Malfatti, S., Do, L. Land, M. L., Pelletier, D. A., Beatty, J. T., Lang, A. S., Tabita, F. R., Gibson, J. L., Hanson, T. E., Bobst, C., Torres, J. L., Peres, C., Harrison, F. H., Gibson, J., and Harwood, C. S. 2004. Complete genome sequence of the metabolically versatile photosynthetic bacterium Rhodopseudomonas palustris. Nat. Biotechnol. 22:55-61.

Miché, L., Bouillant, M. L., Rohr, R., Sallé, G., and Bally, R. 2000. Physiological and cytological studies on the inhibition of Striga seed germination by the plant growth-promoting bacterium Azospirillum brasilense. Eur. J. Plant Pathol. 106:347-351.

Neuer, G., Kronenberg, A., and Bothe, H. 1985. Denitrification and nitrogen fixation by Azospirillum. III. Properties of a wheat-Azospirillum association. Arch. Microbiol. 141:364-370.

Philippot, L. 2002. Denitrifying genes in bacterial and Archaeal genomes. Biochim. Biophys. Acta 1577:355-376.

Philippot, L., Clays-Josserand, A., and Lensi, R. 1995. Use of Tn5 mutants to assess the role of the dissimilatory nitrite reductase in the competitive abilities of two Pseudomonas strains in soil. Appl. Environ. Microbiol. 61:1426-1430.

Pii, Y., Crimi, M., Cremonese, G., Spena, A., and Pandolfini, T. 2007. Auxin and nitric oxide control indeterminate nodule formation. BMC Plant Biol. 7:21.

Poole, R. K., and Hughes, M. N. 2000. New functions for the ancient globin family: Bacterial responses to nitric oxide and nitrosative stress. Mol. Microbiol. 36:775-783.

Pothier, J. F., Wisniewski-Dyé, F., Weiss-Gayet, M., Moënne-Loccoz, Y. and Prigent-Combaret, C. 2007. Promoter trap identification of wheat seed extract-induced genes in the plant growth-promoting rhizobacterium Azospirillum brasilense Sp245. Microbiology 153:3608-3622.

Priemé, A., Braker, G., and Tiedje, J. M. 2002. Diversity of nitrite reductase (nirK and nirS) gene fragments in forested upland and wetland soils. Appl. Environ. Microbiol. 68:1893-1900.

Prigent-Combaret, C., Blaha, D., Pothier, J. F., Poirier, M. A., Vial, L., Wisniewski-Dyé, F., Bally, R., and Moënne-Loccoz Y. 2008. Physical organization and phylogenetic analysis of $a c d R$ as leucine-responsive regulator of the 1-aminocyclopropane-1-carboxylate (ACC) deaminase gene acdS in phytobeneficial Azospirillum lipoferum 4B and other Proteobacteria. FEMS (Fed. Eur. Microbiol. Soc.) Microbiol. Ecol. In press.

Rees, E., Siddiqui, R. A., Koster, F., Schneider, B., and Friedrich, B. 1997. Structural gene (nirS) for the cytochrome $c d l$ nitrite reductase of Alcaligenes eutrophus H16. Appl. Environ. Microbiol. 63:800-802.

Romero, D., Brom, S., Martinez-Salazar, J., Girard, M. L., Palacios, R., and Davila, G. 1991. Amplification and deletion of a nod-nif region in the symbiotic plasmid of Rhizobium phaseoli. J. Bacteriol. 173:24352441

Sambrook, J., Fritsch, E. F., and Maniatis, T. 1989. Molecular Cloning: A Laboratory Manual. 2nd ed. Cold Spring Harbor Laboratory Press, New York, NY, U.S.A.

Schwintner, C., Sabaty, M., Berna, B., Cahors, S., and Richaud, P. 1998. Plasmid content and localization of the genes encoding the denitrification enzymes in two strains of Rhodobacter sphaeroides. FEMS (Fed Eur. Microbiol. Soc.) Microbiol. Lett. 165:313-321.

Sharma, S., Aneja, M. K., Mayer, J., Munch, J. C., and Schloter, M. 2005. Diversity of transcripts of nitrite reductase genes (nirK and nirS) in rhizospheres of grain legumes. Appl. Environ. Microbiol. 71:2001-2007.

Vial, L., Lavire, C., Mavingui, P., Blaha, D., Haurat, J., Moënne-Loccoz, Y., Bally, R., and Wisniewski-Dyé, F. 2006. Phase variation and genomic architecture changes in Azospirillum. J. Bacteriol. 188:53645373.

Vieille, C., Onyeocha, I., Galimand, M., and Elmerich, C. 1989. Homology between plasmids of Azospirillum brasilense and Azospirillum lipoferum Pages 165-172 in: Nitrogen Fixation with Non-Legumes. F. A. Skinner, ed. Kluwer Academic Publishers, Dordrecht, The Netherlands.

Zhang, J. 2003. Evolution by gene duplication: An update. Trends Ecol. Evol. 18:292-298.

Zumft, W. G. 1997. Cell biology and molecular basis of denitrification. Microbiol. Mol. Biol. Rev. 61:533-616.

\section{AUTHOR-RECOMMENDED INTERNET RESOURCES}

National Center for Biotechnology Information BLAST database: www.ncbi.nlm.nih.gov/BLAST/

National Institute of Infectious DiseasesCUPlot Genus chooser database: nocardia.nih.go.jp/cuplot/

Institut Pasteur FUZZNUC database: mobyle.pasteur.fr/cgi-bin/MobylePortal/portal.py?form=fuzznuc

Berkeley Drosophila Genome Project Neural Network Promoter Prediction server: www.fruitfly.org/seq_tools/promoter.html

Center for Biological Sequence (CBS) Analysis SignalP server: www.cbs.dtu.dk/services/SignalP/

CBS TMHMM server: www.cbs.dtu.dk/services/TMHMM/

Molecular Evolutionary Genetics Analysis website: www.megasoftware.net/

A. brasilense $\mathrm{Sp} 245$ genome sequencing data: genomics.ornl.gov/research/azo 